\title{
High school students' argument patterns in online peer feedback
}

\author{
Lisbeth Amhag \\ Faculty of Education and Society \\ Malmö University, SWEDEN
}

The study focuses on strategies for how online course outlines can be designed to improve the use of collaborative peer feedback in distance education and how distance students can learn to use argumentation processes as a tool for learning. For ten weeks, 30 student teachers studied the web-based 15 credit course Teacher Assignment. Data was collected from five student groups' asynchronous argumentation, relating to authentic cases of teacher leadership. Focus was placed on the extent to which students used own and others' texts meaning content in the discussion forum and how the content can be analysed. A close investigation of the dialogical argument patterns $(\mathrm{N}=253)$ in their peer feedback shows the extent to which students distinguish, identify and describe the meaning content that emerge in collaboration with other students in an online setting as an important aspect. The dialogue patterns that developed are illustrated in selected excerpts.

\section{INTRODUCTION}

The background of this research is to improve the use of collaborative peer feedback in distance education, which can promote reflective learning and development in students, as well as their critical ability. Peer feedback uses in this study as information provided by students with aspects of each one's understandings as well alternative strategies and solutions based on literature. University assignments as reports, articles and project presentations are more complex work. Students need to have emphasis on the learning processes in writing, inquiring and problem solving. A practical benefit of implementing collaborative peer feedback is that the feedback becomes available during the learning process and in much larger quantities, than the teacher could ever provide alone. Indeed, the importance of developing critical reasoning and self-reflective learning has been highlighted in several studies within the field of distance learning and education (e.g. Vonderwell, 2003; Finegold \& Cooke, 2006; Wegerif, 2006; Swann, 2010). While many models are available for content analysis of asynchronous discussion groups and the design of online activities to promote e-learning (De Wever et al., 2006; Schrire, 2006; Strijbos et al., 2006; Weinberger \& Fischer, 2006; Sun et al., 2008), there are considerably fewer models that analytically investigate the meaning and quality of peer feedback.

A general overview of the literature from the last decade of online learning research shows that the research design in most studies in the area primarily involved experimental, descriptive and iterative studies (Suthers, 2006). Researchers have examined the technical opportunities, how individual learning can be described and explained and compared how learning is developed in campus courses and in online courses. A frequent pedagogical problem in web-based teaching, discussed by Stahl and Hesse (2008), and Garrison and Arbaugh (2007), is that students and teachers mainly focus on the individual learning process. Self-regulated learning is often done through using web-based tools and wireless technology module systems on their own is not enough.

Another educational problem, described by Stahl and Hesse (2008), is that students and teachers tend to focus on procedural learning and ignore the conceptual learning intended by the curriculum designers. These courses tend to result in relatively superficial or unreflective re-productions among both individual students and student groups. The dialogues investigated in these studies soon assume the character of transmitting 'information'. They become a simple confirmation of what others already have written, and therefore the participants do not succeed in developing deeper knowledge construction. For example 
In Handbook of Research on Didactic Strategies and Technologies for Education: Incorporating Advancements, pages 711-723, 2 Volumes. http://www.igi-global.com/book/didactic-strategies-technologies-education/66392

Erduran and Villamanan's (2009) study indicates that only $35 \%$ of engineering students' written arguments were valid. According to other researchers, academic education should place value and emphasis on the processes of argumentation, engaging in collective higher-order and critical thinking, and forms of reflective interaction that support students' ability and motivation to cooperate in effective ways (Meyer, 2003; Schellens \& Valcke, 2005; Wegerif, 2007; Richardson \& Ice, 2010).

\section{Context}

The present study follows distance student teachers at the Faculty of Education and Society, Malmö University, located at the southern tip of Sweden in Skåne County. Malmö is Sweden's third biggest city, and one of the most multicultural places in Europe. Malmö University has 24000 students, among them are $18 \%$ studying at distance. A clear trend worldwide is that distance education in whole or in part is organized with support of online learning environments, is steadily increasing and is currently the higher education sector that is growing fastest (ICDE, 2009). Swedish surveys show that one of five students is currently studying in whole or in part at distance (Högskoleverket, 2010). The development of distance education has thus resulted in a new way of teaching and to learn in and with and is important for all lifelong learning

\section{AIMS}

The present study is based on Bakhtin's theoretical framework of dialogues $(1981 ; 1986,2004 a ; 1986$, 2004b), as well Toulmin's argument pattern (1958). According to these perspectives learning always arises as a product of a social community of practice where people are involved in different types of dialogue processes to create meaning. The element that distinguishes socio-cultural perspective and Bakhtin's theoretical framework of dialogues from the majority of other perspectives is that it is not possible to understand people's learning and development solely from individual actions or development. Dialogue exchange is a dynamic process, and many individual actions and complex chains of utterances combine to produce effects. Our general aim is to inquire the understanding of socio-cultural perspective of learning and development (Wertsch, 1991; 1998; Wenger, 1998).

When looking for studies on peer learning, Dochy et al. (1999) and Topping (2005) emphasize that by assessing the work of fellow students, students also learn to evaluate their own work. Producing and receiving peer feedback have a considerable benefit to them, as it gives them opportunity to account for the time and effort engaging in the learning process of peer feedback. This view is also supported by Shekary and Tahririan (2006), who state that peer assessment in language-related episodes (LRE) resembles any other form of collaborative learning. LREs are mini-dialogues, in which students ask or talk about language, and either explicitly or implicitly asks questions of their own language use or that of others. They conclude that LRE offers students the potential to develop new knowledge and a greater understanding. Most of use to students was the nature of acceptance, not its mere presence.

Other studies illustrate the potential and voices in online peer feedback as the range of meaningmediating possibilities, as an active tool with self-reflective and interdependent arguments and thoughts, where each student can contribute with his or her own expertise and receive new information and experiences from others (e.g. Dysthe, 2002; Amhag \& Jakobsson, 2009; Amhag, 2010; 2011). Saunders (1989) provides an alternative point of view involving the combination of two factors. The first what students do together with the tasks assigned to them as collaborators, and the second the roles and responsibilities the students assume as collaborators and the interactive structure underlying the activity. This, is peer assessment and is often more limited than other forms of collaborative learning in the sense that it generally offers a lower degree of interactivity. Saunders calls this process as "co-responding" and affects students' possibilities for interactive meaning making and collaborative knowledge construction.

\section{MAIN FOCUS OF CHAPTER}

The study involved following one student group and monitored 30 student teachers (Women=19, Men=11) in the first semester at the School of Teacher Education, 90 credits. Data was collected from the student 
In Handbook of Research on Didactic Strategies and Technologies for Education: Incorporating Advancements, pages 711-723, 2 Volumes. http://www.igi-global.com/book/didactic-strategies-technologies-education/66392

teachers' peer feedback and argumentations of one assignment $(\mathrm{N}=253)$ and from the first 15 credit webbased training course, 'Teacher Assignment'. In the first course assignment, about school development in their subject, the students had trained providing peer feedback in their groups. The study focuses the second training course assignment, where the students worked both individually and collaboratively with 31 cases of teacher leadership (one official case and one from each student). The students were divided into groups, with five to seven individuals in each. Each group included a mix of both women and men. The students were required to first submit their own particular contribution to the assignments. Afterwards, they had to give peer feedback and discuss the contributions of the other members of their group, over a period of a week. The purpose of the assignments was to start a discussion which made use of argumentation theory, which covered topics including different solutions to the underlying problems in the content of the assignments and relate to own experiences and literature.

In order to shed more light on the meaning and quality of collaborative peer feedback online, this chapter aims to investigate the extent to which students use their own and others experiences, claims and data to develop critical thinking, as well as peer feedback ability, individual as collective, as a tool for learning. Additionally, the aim is to develop patterns of qualitative peer feedback, which involves them distinguishing, identifying and describing the meaning content that emerge in collaboration with others in an online learning setting, both directly and retrospectively as an important aspect. Response ability is here related to a concrete answer to a specific text in order to become a more conscious writer. Argumentation ability is related to the process of assembling and reassembling different components of the students' own and others' words and meanings. There is also a need for the students to understand the "ground rules" of peer feedback and to respond to this by arguing and discussing with one another in a reasonable way the points that arise. According to Scheuer et al. (2010), students not only need to "learn to argue" or "learn to respond", they also need to learn good responding and argumentation practices, through aspects of each one's understandings as well alternative strategies and solutions about specific topics. In other words, collaborative peer feedback for online learning has the benefit of facilitating the practicing of responding and argumentation skills that supports critical thinking, as well as other important aspects in collaboration with others.

\section{RESOURCES}

The study included a team of three teachers at the Faculty of Education and Science, Malmö University around the students during the course, but the structure of the course content was already established and the course was completed when the research began after the students were given the study their permission. The web-based learning environment, It's Learning (http://www.itslearning.co.uk) is a commercial platform. Here can student share their assignments in discussion-forums, as in this study to use and evaluate their own and others' web-based peer feedback, both directly and retrospectively. The written asynchronous peer feedback in their discussion-forums is analysed based on Bakhtin's theoretical framework of dialogues (1981; 1986, 2004a; 1986, 2004b), as well Toulmin's argument pattern (1958). Teachers and students can also create pages for study groups, share their interests on blogs, take part in debates online and in audio/video conferences, upload videos and pictures they make and showcase their work in their own ePortfolios for formative purposes.

\section{SPECIFIC AIMS}

The aim is to investigate the quality of students' web-based written peer feedback, and how students can be encouraged to use and evaluate their own and others' web-based peer feedback, both directly and retrospectively. Additionally, the aim is to develop analytical dialogic models, that can be used to distinguish, identify and describe the meaning content and voices of the students' peer feedback that emerge in social and dialogic interactions in collective asynchronous dialogues, in a university web-based learning environment called It's Learning. 
In Handbook of Research on Didactic Strategies and Technologies for Education: Incorporating Advancements, pages 711-723, 2 Volumes. http://www.igi-global.com/book/didactic-strategies-technologies-education/66392

\section{DEVELOPMENT STAGES}

The first phase of analysis and interpretation of the students' meaning content in the online peer feedback, the following quotation by the Russian linguist Mikhail Bakhtin's theoretical framework of dialogues (1981; 1986, 2004a; 1986, 2004b) was used and implemented: "as a neutral word of a language, belonging to nobody, as an other's word, which belongs to another person and is filled with echoes of the other's utterance; and, finally, as my word, for, since I am dealing with it in a particular situation, with a particular speech plan, it is already imbued with my expression" $(1986,2004 \mathrm{~b}$, p. 88). The first aspect is the neutral word that reflects the world of others, in the sense of more general meanings. This word is not built on specific words from literature or personal experiences. The second aspect is others' ${ }^{\prime}$ word, which is filled with echoes of others' voices, based on others' experiences and reasoning from others' texts, including references and paraphrases of other people's words from literature. Others' words have been created in another context. They are negotiated, and confirm a certain meaning relating to the argument at hand, but they do not originate in the person him/herself, and are not necessarily related to the person's own experience. Finally, the third aspect is $m y$ word, because the speaker or writer has experience of a particular situation, and connects a certain line of reasoning with internal reflections and feelings. A summary of Bakhtin's multiple voices is outlined in Figure 1.

\begin{tabular}{|c|c|}
\hline Multiple voices & Patterns of meaning in peer feedback \\
\hline $\begin{array}{l}\text { 1. Neutral word of a } \\
\text { language }\end{array}$ & $\begin{array}{l}\text { - reproduces other people's world view } \\
\text { - aims at any general meanings and thinking } \\
\text { - is not built on words from literature or personal experiences }\end{array}$ \\
\hline 2a. Others' word & $\begin{array}{l}\text { - reproducing reproductions of previous voices } \\
\text { - contains echoes of other voices, dialogic overtones } \\
\text { - explicit voices can be heard presenting voices } \\
\text { - the voices do not originate in the person himself }\end{array}$ \\
\hline $\begin{array}{l}\text { 2b. Others' word from } \\
\text { literature } \\
\text { [my addition] }\end{array}$ & $\begin{array}{l}\text { - reproducing reproductions of other authors' voices } \\
\text { - drawing on other subject experience and reasoning from other texts } \\
\text { - references to and paraphrases of other people's words from literature, expressing } \\
\text { these in their own words } \\
\text { - creating, negotiating and confirming the meaning }\end{array}$ \\
\hline 3. My word & $\begin{array}{l}\text { - carries internal reflections and feelings } \\
\text { - contains their own and others' voices, arguments, justifications, contradictions, } \\
\text { - experience etc. as appropriated to the speaker's own words } \\
\text { - constructs and reconstructs a mutual meaning or a part of it } \\
\text { - creating, negotiating and confirming the meaning }\end{array}$ \\
\hline
\end{tabular}

Figure 1: Summary of multiple voices and patterns of meaning in collaborative peer feedback.

The analysis focused on taking into account that every utterance, spoken or written, always is formed by a voice, and expressed from a particular viewpoint or perspective (Bakhtin, 1980, p. 293). Voice shall here be understood as person's utterance, including meaning of own and others' words from different contexts, and expressed from a particular viewpoint or perspective. Bakhtin (1981, p. 427) talks about a 'discourse' [Rus. slovo] in the dialogue, and points to social and ideological differences within a single language. In Bakhtin's account, the notion of utterance is inherently linked with that of voice. It is "the speaking personality, the speaking consciousness. A voice always has a will or desire behind it, its own timbre and overtones" (1981, p. 434). In other words, the utterances contain dialogic overtones, which can, for example, be composed of assertions regarding the world, ontological conclusions, or hypotheses regarding a phenomenon. Bakhtin emphasizes that language has multiple functions, and every utterance, with its attitudes and values, places humans in a cultural and historical tradition.

The interpretation of the students' meaning content in the online peer feedback was Bakhtin's theoretical dialogic framework combined with Toulmin's argument pattern. Toulmin (1958, pp. 98, 101, 103) describes how writers and readers can deal with texts, and how they can use the resources of texts to 
In Handbook of Research on Didactic Strategies and Technologies for Education: Incorporating Advancements, pages 711-723, 2 Volumes. http://www.igi-global.com/book/didactic-strategies-technologies-education/66392

determine what they mean - or rather, some possible meanings - and how it can be achieved with an argument model containing six elements. A summary is given in Figure 2.

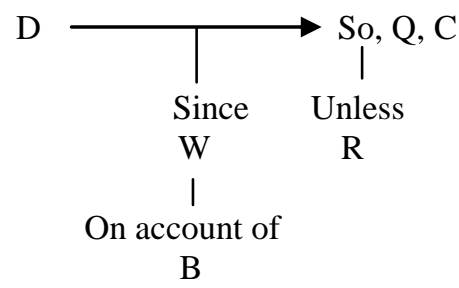

Figure 2. Summary of Toulmin's argument pattern (Toulmin, 1958, p. 104)

Three elements are mandatory, while the remaining three are more voluntary or optional, since they occur often, but not always. The basic argument model consists of three mandatory elements: C (claim), D (data) and $\mathrm{W}$ (warrant). The extended argument model includes three more optional elements; Q (qualifier), R (rebuttal) and B (backing). A revised version of Toulmin's argument pattern with the mandatory and optional elements, inspired by developments of the specific features in the TAP made by Kneupper (1978) and Simon et al. (2006), is given in Figure 3.

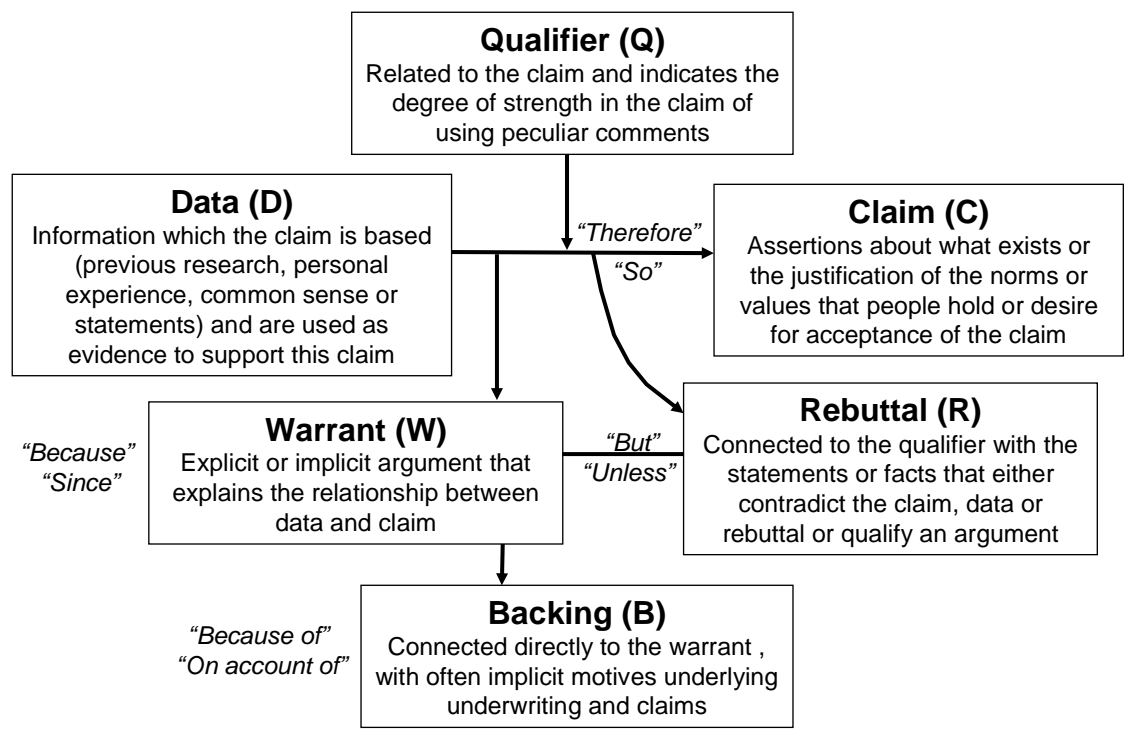

Figure 3. Revised version of Toulmin's argument pattern (TAP).

The task is to show students how to present their ideas in an understandable and coherent manner, based on these data and the claims of the original opinion. The first mandatory element, claim (C), is a superior standpoint, with a relationship to any determination or assertions about what exists, or the justification of the norms or values that people hold or desire for acceptance of the claim. The second mandatory element, data (D), is the information which the claim is based on, and may consist of previous research, personal experience, common sense, or statements used as evidence to support the claim. The third mandatory element, warrant (W), is explicit or implicit argument that explains the relationship between data and claim, for example, with words such as because or since. The first optional element, qualifier (Q), is related to the claim, and indicates the degree of strength in the claim of using peculiar comments, for example, with words such as probably, maybe, therefore or so. The second optional element, rebuttal (R), is connected to the qualifier $(\mathrm{Q})$, providing statements or facts that either contradict the claim, data or rebuttal, or qualify an argument, with words such as but and unless. The third optional element, backing 
In Handbook of Research on Didactic Strategies and Technologies for Education: Incorporating Advancements, pages 711-723, 2 Volumes. http://www.igi-global.com/book/didactic-strategies-technologies-education/66392

(B), can be connected directly to the warrant (W), with often implicit motives underlying claims, expressed with words such as because of or on account of. According to Toulmin, all terms of the basic argument model (C, D \& W) are required to describe or analyse the argument.

At first focus was placed on specific features: the extent to which students had made use of Toulmin's mandatory elements; data, claims and warrants, the optional elements; qualifiers, rebuttals and backings (which in English are often presented by characteristic words, such as because, so or but), and how the different elements in the same argument are related to each other. However, this phase of the analysis does not show how the elements relate, explicitly or implicitly, to other arguments in a chain of utterances. The dialogical interaction with other claims, data, warrants, etc. cannot be distinguished, as such, in the first phase of analysis, or the creation of meaning, when two or more voices or discourses encounter each other, as Bakhtin emphasizes. The second focus involved discovering and identifying another set of relevant aspects, using an approach based on Bakhtin's theories of double-voiced discourse (1984, p. 185), which inevitably occurs under conditions of dialogic interactions. On the one hand, Bakhtin broadens the concept of language, by pointing to the fact that dialogic interaction and a dialogic relation are inherent to all communication. On the other hand, Toulmin's cognitive and practical argument pattern makes the structure visible that connects various data, claims and support for the arguments to each other. Using a combination of these perspectives thus makes the analysis of written asynchronous responses and arguments more explicit, reliable and valid.

\section{SPECIAL ASPECTS OF THE EXPERIMENT}

The implications and results that the studies highlights are that it is in collaborative peer feedback understanding of different meaningful meanings is clarified and develops. It may be concluded that using assignments drawing on authentic assignments and cases with collaborative peer feedback, is indeed a way to make the words more genuine and living (Bakhtin, 1984). The peer feedback strategies with group activities over a specific period, where dialogue exchange and collaboration are in focus, opens for the manifestation of written polyphony, because the students' independent voices in their peer feedback have the same value or authority as authors in books (Møller Andersen, 2002; 2007). A more complex peer feedback character develops when the content is confronted with others' utterances, consisting of comparing different statements and justifying opposing words and voices. There may be direct and explicit opinions in the contributions and assertions about what exists, or statements that contradict, confirm, complement or develop further. Common sense or implicit or unspoken motives may also be expressed.

\section{Strong points, failings and critical issues}

Using Bakhtin's theories of dialogues (1981; 1986, 2004b; 1986, 2004a), combined with Toulmin's argument pattern (1958), appears to show a new quality dimension in which the specific words with voices and elements and voices in the online peer feedback. This is an addition to the dialogical relations between them, which makes them more explicit and more visible. Students also learn to evaluate their own work when they are producing and receiving peer feedback. In this regard, the form of discourse has resulted in the students' peer feedback consisting partly of their own words and voices, and partly of others'. The act of simply learning to use web-based tools and wireless technology module systems was shown to not be enough. It is still a challenge to provide a web-based environment conducive for learning and development, individual as collective.

\section{Solutions and Recommendations}

The study shows the importance of dialogic interaction with collaborative peer feedback. The students had before trained providing individual feedback in their groups. In the following excerpt, the argument patterns in their collaborative peer feedback will be distinguished, identified and described, as well as the dialogical relations between written contributions. The students' names are fictitious. The excerpt, in Figure 4, is Chris' answer to one of his group members, about an authentic case of a boy's transfer to another school. 
In Handbook of Research on Didactic Strategies and Technologies for Education: Incorporating Advancements, pages 711-723, 2 Volumes. http://www.igi-global.com/book/didactic-strategies-technologies-education/66392

The claim in this excerpt is Chris' standpoint that the fact that the boy had been transferred to another school and that the situation was also linked to the boy's natural reaction to their lack of interest and the school's inability to solve it. The boy cannot trust anyone - neither parents nor school. The data are part of the claim, which is supported in the literature on the important interactions between social sensitivity and trust. The warrant is here explicit, because it explains the importance of the relationship between school and home and between teachers' teaching and students' schoolwork. Chris' statement: "I am aware that there is a great responsibility" is the backing in this argument, because of the meaning in the following: What I write is highlighted in the literature and therefore, I write it in my post. If we look at the qualifier of the claim in this example, it is that the teacher should create a more profound and responsible relationship with the student. Finally, the contribution contains a rebuttal, in the qualified statement which begins with but: "But it may be needed in order to succeed with difficult students". 'Backing', 'qualifier' and 'rebuttal' are all optional elements, which are related to the mandatory elements, 'claim', 'data' and 'warrant'.

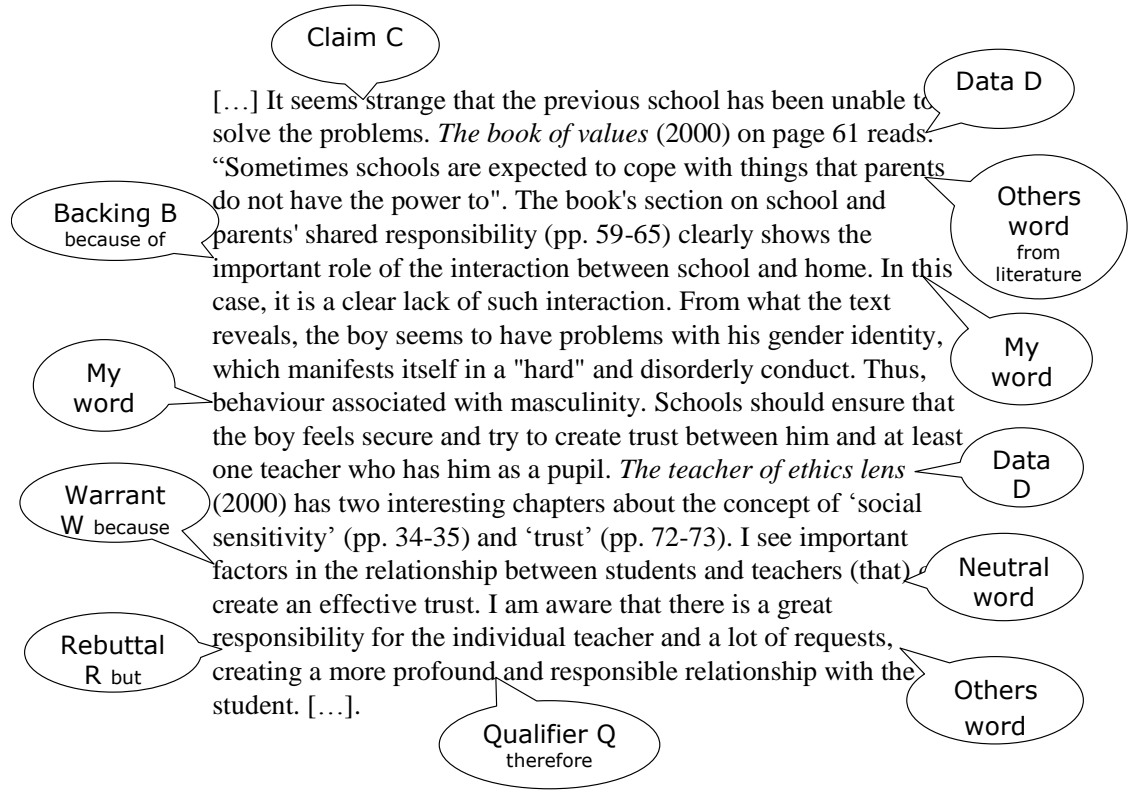

Figure 4: The specific elements and words with different voices in the meaning content of the argument.

If we look at the same excerpt above, is it easy to see that the analysis that only uses Toulmin's argument pattern failed to show that meaning is something that is created between others' words or utterances. According to Bakhtin (1986, 2004b), every utterance, is always formulated by different voices with meanings of others' words in different contexts: a discourse in the dialogue. The links in this chain of voices can be observed, including those claims, data and warrants of neutral words, others' words and my words that are used as evidence. The claim in Chris' standpoint that it "feels like unengaged manners of parents solving their children's problem" is an example of his own word, with internal reflections and feelings. The data is an example of basing argument on support from the literature of others ' word, which is filled with echoes of other people's words and reasoning from other texts. A neutral, more general word is exemplified when Chris writes "I am aware that there is a great responsibility to the individual teacher". The warrant has a dialogical relationship between Chris' argument with data and claims, that explains the importance of the relationship between truth, love, hate, deceit, distrust, respect, social sensitivity, trust, and so forth, like in the excerpt above between parents and child, and between school and home. The backing, qualifier and rebuttal include all kinds of individually established semantic ties with relations between subjects and objects (Bakhtin, 1986, 2004a, p. 138). In short, the excerpt illustrates that the development of meaning - which is the basis of learning - is not created from a single word or from the language system alone, but arises in the relationship and interaction between my word and others' word. 
In Handbook of Research on Didactic Strategies and Technologies for Education: Incorporating Advancements, pages 711-723, 2 Volumes. http://www.igi-global.com/book/didactic-strategies-technologies-education/66392

The result shows that each peer feedback is an intersection of words, where at least one aspect of others' words can be read, and each utterance can be considered as an answer to preceding utterances, that is, it has addressivity (Bakhtin, 1986, 2004b). This addressivity is made more possible in collaboration with other students and can be compared with Hattie and Timperley's (2007) three major questions of effective feedback: Where am I going? (What are the goals?), How am I going? (What progress is being made toward the goal?), and Where to next? (What activities need to be undertaken to make better progress?). The questions correspond to the design of feed back, feed up and feed forward and they are partly dependent on to reduce the gap across the level of task performance, the level of process of understanding how to do a task, the metacognitive process level, and/or the self level. The combination of what students do together with the tasks assigned to them as collaborators, and the roles and responsibilities the students assume as collaborators and the interactive structure underlying the activity offer the potential to develop and expand the space of learning and understanding (Saunders, 1989; van del Pol et al., 2008).

\section{CONCLUSION}

This chapter aimed to find how the quality of peer feedback can be analyzed and practiced online in which students' in collaboration with others can use own and others' texts meaning content as a tool for learning. The dialogue patterns that developed during the study provide examples of how the meaning content in collaborative peer feedback can be distinguished, identified and characterized. The analysis offers students, student groups and teachers further insights into how they can use Bakhtin's theories of doublevoiced discourse. The use of Toulmin's practical argument model, also showed greater context of how "arguing to learn" and "responding to learn" can be promoted, evaluated and developed in online education at distance.

A strategy to promote collaborative peer feedback with critical review and meta-reflection can have three main benefits. The first is to enable the students after the peer feedback processes to compile their own posts and self-assesses them with further reflection, theoretically and practically. The second option is to allow the students compile others' peer feedback and analyze them further, theoretically and practically. A further strategy to promote collaborative and dialogic exchange may be to let peer feedback and critical review of and between students be a part of the examination. These processes creates the conditions for students to find structure and patterns of how peer learning and reasoning can be shaped, negotiated and confirmed "between I and other" in an online context. Comparing to Lähteenmäki's (2004) term "use theory of meaning" the situated "space" is expanding with meaningful learning, when students begin to reflect on the meaning content and when different extents attain an understanding, agreement and experience. In this manner, builds Bakhtin's theories of dialogue bridges across the cognitive and the social-individual divide.

\section{REFERENCES}

Amhag, Lisbeth. (2010). BETWEEN I AND OTHER. Web-based student dialogues with arguments and responses for learning. Malmö University: Malmö Studies in Educational Sciences: Doctoral Dissertation Series 2010:57.

Amhag, Lisbeth. (2011). Students' Argument Patterns in Asynchronous Dialogues for Learning. In Research Highlights in Technology and Teacher Education 2011 (pp. 137-144): Ed/ITLib Digital Library http://storefront.acculink.com/aace.

Amhag, Lisbeth, \& Jakobsson, Anders. (2009). Collaborative Learning as a Collective Competence when Students Use the Potential of Meaning in Asynchronous Dialogues. Computers \& Education, 52(3), 656-667.

Bakhtin, Mikhail M. (1981). Discourse in the novel (Caryl Emerson \& Michael Holquist, Trans.). In Michael Holquist (Ed.), The Dialogic Imagination: Four Essays by M. M. Bakhtin (pp. 259-422). Austin: University of Texas Press. 
In Handbook of Research on Didactic Strategies and Technologies for Education: Incorporating Advancements, pages 711-723, 2 Volumes. http://www.igi-global.com/book/didactic-strategies-technologies-education/66392

Bakhtin, Mikhail M. (1984). Discourse in Dostoevsky. In Problems of Dostoevsky's Poetics (pp. 181272). Minneapolis: University of Minnesota Press.

Bakhtin, Mikhail M. (1986, 2004a). From Notes Made in 1970-71 (Vern W McGee, Trans.). In Caryl Emerson \& Michael Holquist (Eds.), Speech Genres \& Other Late Essays (Vol. 9, pp. 132-158). Austin: University of Texas Press.

Bakhtin, Mikhail M. (1986, 2004b). The Problem of Speech Genres (Vern W McGee, Trans.). In Caryl Emerson \& Michael Holquist (Eds.), Speech Genres \& Other Late Essays (Vol. 9, pp. 60-102). Austin: University of Texas Press.

De Wever, B., Schellens, T. , Valcke, M. , \& Van Keer, H. . (2006). Content analysis schemes to analyze transcripts of online asynchronous discussion groups: A review. Computers \& Education, 46(1), 6-28.

Dochy, F., Segers, M., \& Sluijsmans, D. (1999). The use of self-, peer- and co-assessment in higher education: a review. Studies in Higher Education, 24(3), 331-350.

Dysthe, Olga. (2002). The Learning Potential of a Web-mediated Discussion in a University Course. Studies in Higher Education, 27(3).

Erduran, Sibel, \& Villamanan, Rosa. (2009). Cool Argument: Engineering Students' ${ }^{`}$ Written Arguments about Thermodynamics in the Context of the Peltier Effect in Refrigeration. Educacaión quimica, 119-125.

Finegold, Adam R.D., \& Cooke, Louise. (2006). Exploring the attitudes, experiences and dynamics of interaction in online groups. The Internet and Higher Education, 9, 201-215.

Garrison, D. Randy, \& Arbaugh, J.B. (2007). Researching the community of inquiry framework: Review, issues, and future directions. The Internet and Higher Education, 10, 157-172.

Hattie, John, \& Timperley, Helen. (2007). The Power of Feedback. Review of Educational Research, $77(1), 81-112$.

Högskoleverket. (2010). Kartläggning av distansverksamheten vid universitet och högskolor. [Survey of Distance Activity at Colleges and Universities]. Retrieved 2011-01-12. from www.hsv.se.

ICDE, International Council for Open and Distance Education. (2009). Global Trends in Higher Education, Adult and Distance Learning. Retrieved 2011-03-13. from http://www.icde.org/filestore/Resources/Reports/FINALICDEENVIRNOMENTALSCAN05.02.p df.

Kneupper, Charles W. (1978). Teaching Argument: An Introduction to the Toulmin Model. College Composition and Communication, 29(3), 237-241.

Lähteenmäki, Mika. (2004). Between Relativism and Absolutism: Toward an Emergenist Definition of Meaning Potential. In Finn Bostad, Craig Brandist, Lars Sigfred Evensen \& Hege Charlotte Faber (Eds.), Bakhtinian Perspectives on Language and Culture. Meaning in Language, Art and New Media (pp. 91-113). New York: Palgrave Macmillian.

Meyer, Katrina (2003). Face-to-face versus threaded discussions: the role of time and higher-order thinking. Journal of Asynchronous Learning Networks, 7(3), 55-65.

Møller Andersen, Nina. (2002). I en verden affremmende ord. Bachtin som sprogbrugsteoretiker. Denmark: Akademisk Forlag.

Møller Andersen, Nina. (2007). Bachtin og det polyfone. In Rita Therkelsen, Nina Møller Andersen \& Henning Nølke (Eds.), Sproglig polyfoni. Tekster om Bachtin og ScaPoLine. Aarhus: Aarhus Universitetsforlag.

Richardson, Jennifer C., \& Ice, Phil. (2010). Investigating students' level of critical thinking across instructional strategies in online discussions. Internet and Higher Education, 13, 52-59.

Saunders, William. (1989). Collaborative writing tasks and peer interaction. International Journal of Educational Research, 13, 101-112.

Schellens, Tammy, \& Valcke, Martin. (2005). Collaborative learning in asynchronous discussion groups: What about the impact on cognitive processing? Computers in Human Behavior, 21, 957-975. 
In Handbook of Research on Didactic Strategies and Technologies for Education: Incorporating Advancements, pages 711-723, 2 Volumes. http://www.igi-global.com/book/didactic-strategies-technologies-education/66392

Scheuer, Oliver, Loll, Frank , Pinkwart, Niels , \& McLaren, Bruce M. (2010). Computer-supported argumentation: A review of the state of the art. Computer-Supported Collaborative Learning (5), 43-102.

Schrire, Sarah. (2006). Knowledge building in asynchronous discussion groups: Going beyond quantitative analysis. Computers \& Education, 46(1), 49-70.

Simon, Shirley, Erduran, Sibel, \& Osborne, Jonathan. (2006). Learning to Teach Argumentation: Research and development in the science classroom. International Journal of Science Education, 28(2-3), 235-260.

Stahl, Gerry, \& Hesse, Friedrich (2008). The many levels of CSCL. International Journal of ComputerSupported Collaborative Learning, 3(1).

Strijbos, Jan-Willem, Martens, Rob L. , Prins, Frans J. , \& Jochems, Wim M.G. (2006). Content analysis: What are they talking about? Computers \& Education, 46(1), 29-48.

Sun, Pei-Chen, Tsai, Ray J., Finger, Glenn, Chen, Yueh-Yang, \& Yeh, Dowming. (2008). What drives a successful e-Learning? An empirical investigation of the critical factors influencing learner satisfaction. Computers \& Education, 50(4), 1183-1202.

Suthers, Daniel D. (2006). Technology affordances for intersubjective meaning making: A research agenda for CSCL. International Journal of Computer-Supported Collaborative Learning, 1(3).

Swann, Jennie (2010). A dialogic approach to online facilitation. Australasian Journal of Educational Technology, 26(1), 50-62.

Topping, Keith. (2005). Trends in Peer Learning. Educational Psychology, 25(6), 631-645.

Toulmin, Stephen E. (1958). The uses of argument. Cambridge, England: Cambridge University Press.

van der Pol, J., van den Berg, B.A.M., Admiraal, W.F. , \& Simons, P.R.J. . (2008). The nature, reception, and use of online peer feedback in higher education. Computers \& Education 51 (2008) 51(4), 1804-1817.

Wegerif, Rupert. (2006). A dialogic understanding of the relationship between CSCL and teaching thinking skills. International Journal of Computer-Supported Collaborative Learning, 1(1).

Wegerif, Rupert. (2007). Dialogic education and technology: Expanding the space of learning. New York: Springer.

Weinberger, Armin, \& Fischer, Frank. (2006). A framework to analyze argumentative knowledge construction in computer-supported collaborative learning. Computers \& Education, 46(1), 71-95.

Wenger, Etienne. (1998). Communities of Practice - Learning, meaning and Identity. New York: Cambridge University Press.

Wertsch, James V. (1998). Mind as Action. Oxford: Oxford University Press.

Wertsch, James V. (1991). Voices of the Mind. A Sociocultural Approach to Mediated Action. Cambridge: Harvard University Press.

Vonderwell, Selma. (2003). An examination of asynchronous communication experiences and perspectives of students in an online course: A case study. The Internet and Higher Education, 6, 77-90.

Key terms: Peer Feedback; Peer Learning; Collaborative Feedback; Response Ability; Argumentative ability; Distance Learning; Online Learning; Distance Education

\section{Definitions}

Peer Feedback: Information provided by students with aspects of each one's understandings as well

alternative strategies and solutions based on literature

Peer Learning: When assessing the work of fellow students, students also learn to evaluate their own work. Collaborative Feedback: Supporting critical and higher-order thinking, as well as other important learning aspects in collaboration with others.

Response Ability: Related to a concrete answer to a specific text in order to become a more conscious writer.

Argumentative ability: Related to the process of assembling and reassembling different components of the students' own and others' words and meanings. 